University of Nebraska - Lincoln

DigitalCommons@University of Nebraska - Lincoln

Faculty Publications, College of Dentistry

Dentistry, College of

$1-1990$

\title{
Effects of an Air-Powder Polishing System on Orthodontically Bracketed and Banded Teeth
}

\author{
Caren M. Barnes \\ University of Nebraska College of Dentistry, cbarnes@unmc.edu \\ Carl M. Russell \\ University of Alabama School of Dentistry, Birmingham \\ Laurence R. Gerbo \\ University of Alabama School of Dentistry, Birmingham \\ Bobby R. Wells \\ University of Alabama School of Dentistry, Birmingham \\ David Barnes \\ University of Alabama School of Dentistry, Birmingham
}

Follow this and additional works at: https://digitalcommons.unl.edu/dentistryfacpub

Part of the Other Medicine and Health Sciences Commons

Barnes, Caren M.; Russell, Carl M.; Gerbo, Laurence R.; Wells, Bobby R.; and Barnes, David, "Effects of an Air-Powder Polishing System on Orthodontically Bracketed and Banded Teeth" (1990). Faculty Publications, College of Dentistry. 3.

https://digitalcommons.unl.edu/dentistryfacpub/3

This Article is brought to you for free and open access by the Dentistry, College of at DigitalCommons@University of Nebraska - Lincoln. It has been accepted for inclusion in Faculty Publications, College of Dentistry by an authorized administrator of DigitalCommons@University of Nebraska - Lincoln. 
Published in American Journal of Orthodontics and Dentofacial Orthopedics 97:1 (January 1990), pp. 74-81.

Copyright (C) 1990 Elsevier Inc. Used by permission. http://www.sciencedirect.com/science/journal/08895406

Project supported by a grant from Dentsply/Equipment Division, York, Pa.

\title{
Effects of an Air-Powder Polishing System on Orthodontically Bracketed and Banded Teeth
}

\author{
Caren M. Barnes, RDH, MS, ${ }^{*}$ Carl M. Russell, DMD, MS, ${ }^{* *}$ Laurence R. Gerbo, DDS, ** \\ Bobby R. Wells, DMD, MS, ${ }^{* * *}$ and David W. Barnes, DDS*** \\ University of Alabama School of Dentistry, Birmingham, Alabama, USA \\ *Associate Professor **Postdoctoral Fellow, Cariology Program ***Assistant Professor
}

S ince the introduction of air-powder polishing systems in 1977,1 air-powder polishing has been shown to be an efficient and effective method for removal of stain and plaque. ${ }^{2}$ Air-powder polishing systems use air, water, and sodium bicarbonate to deliver a controlled stream that propels specially processed sodium bicarbonate particles to the tooth surface. ${ }^{3-5}$ It has been demonstrated that this increasingly popular technique requires less time and less physical exertion by the operator than polishing with a rubber cup and prophylaxis paste. In addition, no heat is generated with this type of system. ${ }^{2}$

Studies of the air-powder polishing method have examined its efficacy in stain removal ${ }^{2}$ and its effects on soft tissue ${ }^{2,6-12}$ hard tissue, ${ }^{5,13,14}$ and restorative materials. $3,15,16$ William et al. ${ }^{15}$ found that air-powder polishing treatment imparted a nonuniformly roughened surface to enamel. Atkinson et al. ${ }^{5}$ and Toevs, ${ }^{14}$ however, found root surfaces to be smooth after treatment with the airpowder polishing system. Furthermore, this system has been shown to produce some immediate soft tissue trauma. In all of these studies this gingival trauma has been shown to be transient and clinically insignificant. ${ }^{17}$

Although air-powder polishing systems have been shown to be effective, it has been demonstrated that these systems have the potential for removing considerable amounts of resinous restorative material., 315,16 On the other hand, porcelain, amalgam, and gold alloy restorations generally are not significantly affected. ${ }^{15,16}$ However, Barnes and associates did note an erosion of cement from the margin of cast-alloy restorations. ${ }^{3}$

The purpose of this two-part study, based on studies to date that have shown deleterious effects on resinous materials and cement, was to examine the efficacy and effects of an air-powder polishing system on orthodontically bracketed and banded teeth. Orthodontically bracketed and banded teeth certainly provide a greater challenge for routine cleaning that may be met by an air-powder polishing system.
Specifically, this study investigated the time required for removal of stain and plaque from orthodontically bracketed and banded teeth as well as the efficacy of the air-powder polishing system. In addition, the effects of airpowder polishing on composite and zinc phosphate cements used to anchor orthodontic brackets and bands were examined with a scanning electron microscope (SEM).

\section{Methods and Materials}

This study was conducted in two parts. Part I investigated the efficacy and efficiency of the air-powder polishing (APP) method (Prophy-Jet, Dentsply/Cavitron, Long Island City, N.Y.) for removal of stain and plaque from orthodontically bracketed and banded teeth in comparison with a rubber cup and pumice method (RCP). Part II of the study evaluated the effects of the APP method on (1) composite material (Concise orthodontic bonding system, 3M Company, St. Paul, Minn.) used with orthodontic brackets and (2) zinc phosphate cement used with orthodontic bands.

\section{Study Design}

\section{Part I}

By random selection, half the mouth (maxillary and mandibular right or left) in each of 50 patients with orthodontically bracketed and banded teeth was treated with the APP method and the opposite half with the RCP method. These patients were having a routine prophylaxis at the University of Alabama School of Dentistry; they had a minimum of 20 bracketed and banded teeth each, were not on a sodium-restricted diet, and did not have a history of high blood pressure or other cardiovascular disease. Patients ranged in age from 9 to 41 years, with a mean age of 17.5 years.

All 50 patients were examined immediately before and after treatment. All teeth were scored for the 


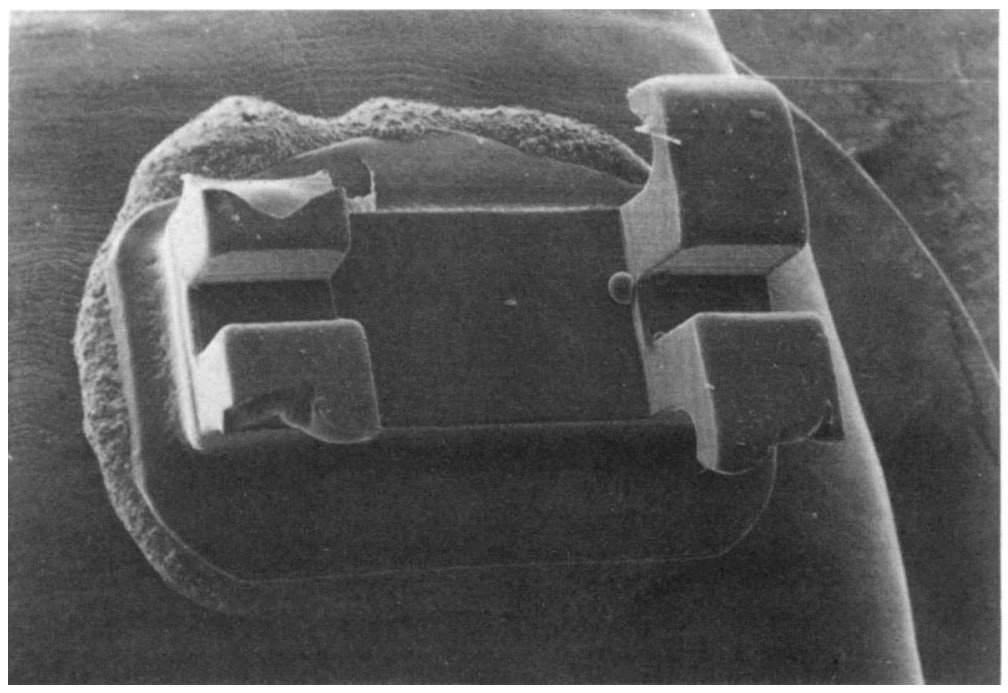

Figure 1. SEM photograph of a replicated bracketed maxillary central incisor treated for 60 seconds with the APP method at 10x magnification. Tie-wings did not completely replicate because of severe undercuts in impression material.

plaque index (PI) of $\mathrm{O}^{\prime}$ Leary ${ }^{18}$ and the stain index (SI) of Greene and Vermillion. ${ }^{19}$ During treatment of each patient, the operator recorded treatment time required by each method to remove stain and plaque; the effectiveness of each technique for removal of dental stain and plaque was recorded by the same examiner, who had no knowledge of treatment conditions.

\section{Part II}

Orthodontic brackets were attached to ten extracted maxillary central incisors with composite, and orthodontic bands were cemented with zinc phosphate cement to ten extracted mandibular first molars. By random selection, the bracketed teeth were placed in five groups (two teeth each) and the ten banded teeth were also randomly placed in five groups (two teeth each). Each treatment group was randomly assigned to exposure to the APP for 5, 10, 15, 30, or 60 seconds.

Before treatment with the APP method, each tooth was positioned in a stabilized mounting device. Treatment was done by the same operator and the air-powder-water stream was directed at a $90^{\circ}$ angle to each bracket and band. Occlusal surfaces of the banded teeth were also treated at a $90^{\circ}$ angle. The handpiece nozzle was kept at a uniform $4 \mathrm{~mm}$ distance from the surface being treated. After treatment of the bracketed and banded teeth, individual impressions were made of each tooth with a polyvinylsiloxane impression material (Reprosil, Caulk Division, Dentsply, Milford, Del.). The impressions were poured with an epoxy resin (Ortho Bond, Vemon-Benshoff Co., Inc., Albany, N.Y.) and coated for viewing with the SEM. SEM photographs were taken at magnifications of $10 \times, 50 \times$, and $100 \times$.
Table I. Plaque score improvement produced by each polishing method

\begin{tabular}{lcc}
\hline Method & Mean & Standard error \\
\hline APP & 72.4 & 2.04 \\
RCP & 59.9 & 2.07 \\
$\Delta$ RCP-APP & -12.6 & 1.83 \\
\hline$n=50$ & &
\end{tabular}

\section{Results}

Part I

The improvement in the plaque score achieved by the APP method was compared with that achieved by the RCP method by means of a paired $t$ test (Table I). The paired $t$ test indicates a significant difference in the two methods $(p=0.0001)$, with the APP method being the most effective for plaque removal.

All of the cases in which stain was not demonstrated before treatment were deleted for obvious reasons. Sixteen cases demonstrated stain. The same analytical procedures used for plaque were used for stain (Table II). The paired $t$ test did not indicate a significant difference in the two methods $(p=0.0866)$ because there was an inadequate number of cases with pretreatment stain. Lack of stain was attributed to the young ages of the majority of patients (mean age, 17.5 years). Therefore, the APP method did not have a significantly better stain-removal performance, but further testing of greater numbers may prove the difference is real. 


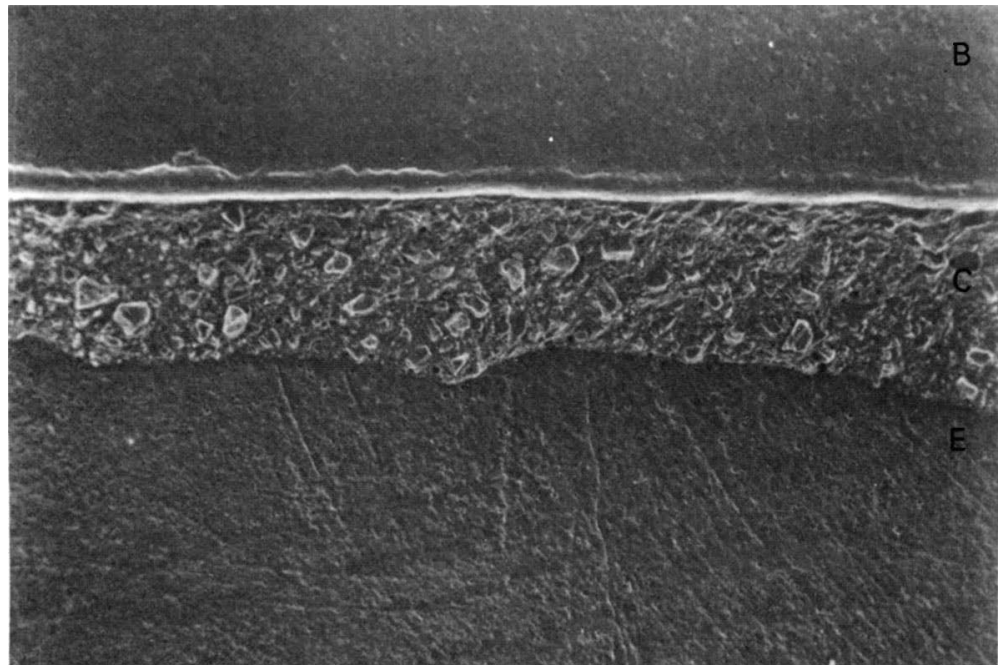

Figure 2. SEM photograph of replica shown in Figure 1, at 50× magnification, after treatment with APP method for 60 seconds. B indicates bracket, $\mathbf{C}$ indicates composite, and $\mathbf{E}$ indicates enamel. Note exposed composite particles and intact margin.

Table II. Stain score improvement produced by each method

\begin{tabular}{lrc}
\hline Method & Mean & Standard error \\
\hline APP & 1.54 & 0.12 \\
RCP & 1.21 & 0.16 \\
$\Delta$ RCP-APP & -0.33 & 0.18 \\
\hline
\end{tabular}

$n=16$

Time required for each method was also analyzed by means of a paired $t$ test (Table III). The RCP method required significantly more time $(p=0.0001)$ than the APP method.

\section{Part II}

The effect of the APP method on composite resin used to bond brackets and on zinc phosphate cement used to attach metal bands is illustrated in a series of scanning electron photomicrographs. Only photomicrographs of brackets and bands treated for 60 seconds are included, as these represented the groups with the most extreme exposure to the APP method. Figures 1, 2 , and 3 show representative photomicrographs for the groups of extracted maxillary central incisors to demonstrate the effects of the APP on the composite resin. As can be seen in Figure 1, the composite resin and its margin remain intact. Figures 2 and 3, taken at magnifications of $50 \times$ and $100 \times$, respectively, demonstrate that while some composite resin matrix has been re-
Table III. Analysis of time required with each polishing method

\begin{tabular}{lcc}
\hline Method & Mean time $(\mathrm{min})$ & Standard error \\
\hline APP & 4.02 & 0.17 \\
RCP & 6.76 & 0.26 \\
$\Delta$ RCP-APP & 2.74 & 0.26 \\
\hline
\end{tabular}

$n=50$

moved to expose composite particles, the integrity of the composite has not been disturbed. Figures 4 and 5 are photomicrographs of the same tooth and bracket before treatment and have been included for comparative purposes.

Figure 6 shows a photomicrograph of the buccal aspect of a banded mandibular first molar and the zinc phosphate cement used to cement it. Figure 7 represents the same banded tooth after treatment with the APP method. As can be seen, although some particles have been exposed, only trace amounts of zinc phosphate have been removed.

The occlusal surfaces of the banded mandibular first molars were also treated with the APP method. Figure 8 represents the occlusal surface of the band and its accompanying zinc phosphate cement before treatment. Figures 9 and 10 represent the same area after treatment with the APP method. The APP method has removed some excess cement and exposed cement particles but has not disrupted the integrity of the cement to the tooth or the cement to the band. 


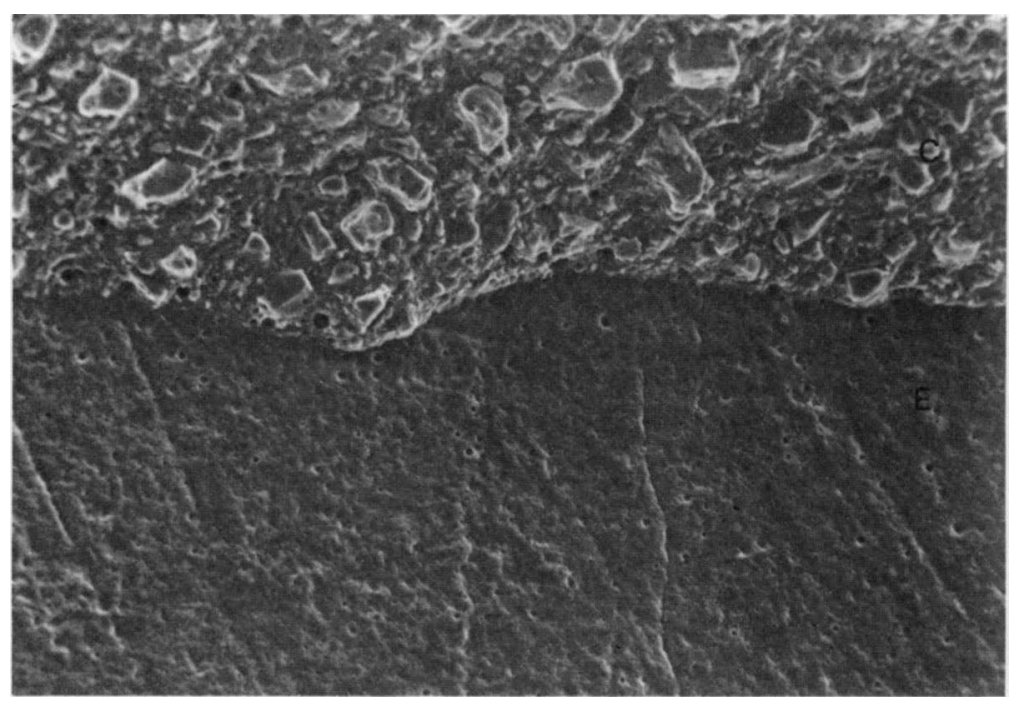

Figure 3. SEM photograph of replica shown in Figures 1 and 2 at 100× magnification. Composite was treated with APP for 60 seconds leaving composite margin intact while having removed enough resin matrix to expose composite particles.

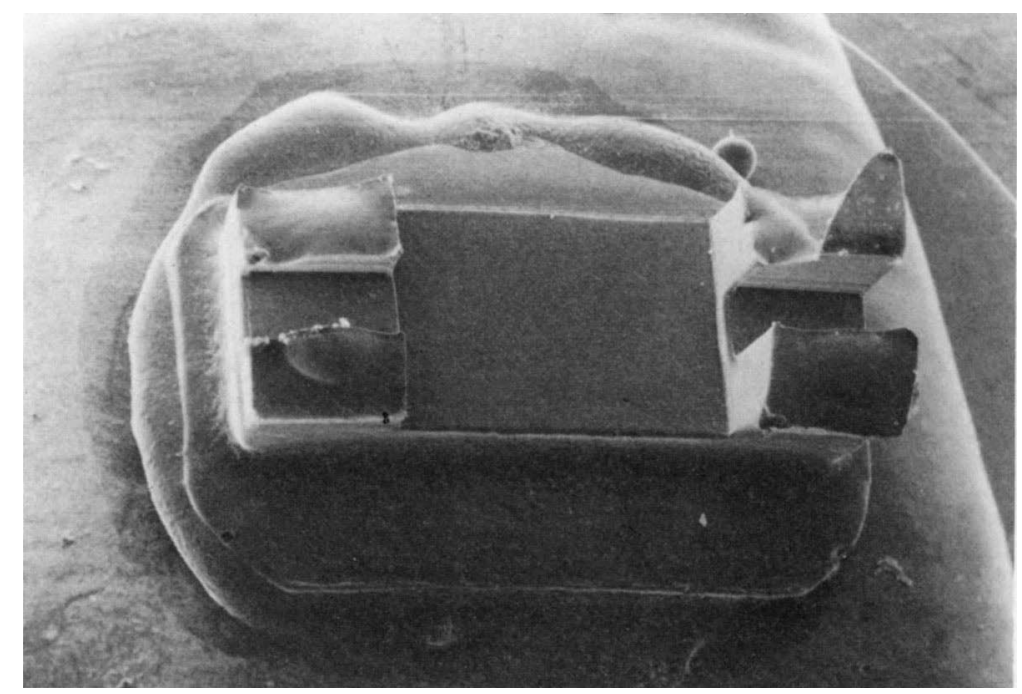

Figure 4. SEM photograph of replicated tooth shown in Figures 1 to 3, before treatment, at $10 \times$ magnification. Tie-wings did not completely replicate because of severe undercuts in impression material.

\section{Discussion}

The results of this study demonstrate that use of an air-powder polishing system is a time-efficient and effective means for removal of plaque from orthodontically bracketed and banded teeth. Additional rubber cup and pumice polishing is required if the same effect as that of the air-powder polishing method is to be achieved. The investigators of this study noted other benefits of the air-powder polishing method in addition to its time efficiency and thoroughness of plaque removal. No orthodontic wires or rubber bands were disturbed with the air-powder polishing method, which was not the case with the rubber cup and pumice method. Patients who had recently undergone orthodontic adjustment did not find the air-powder polishing method to be uncomfort- 


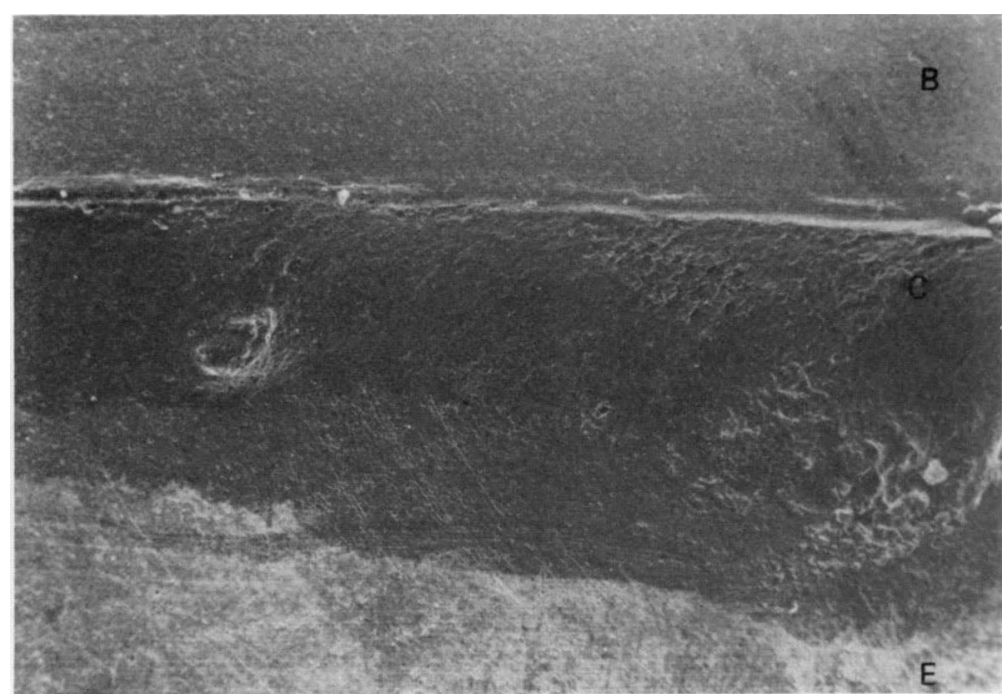

Figure 5. SEM photograph of replicated tooth shown in Figure 4 (before treatment) at 50× magnification, included for comparative purposes. B indicates bracket, $\mathbf{C}$ indicates composite, and $\mathbf{E}$ indicates enamel.

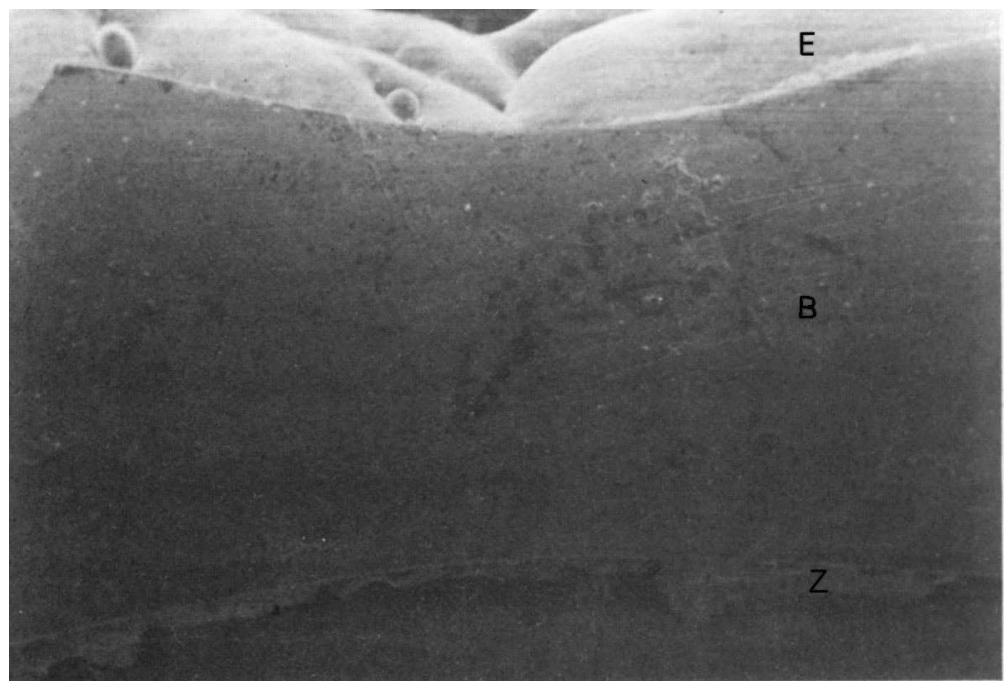

Figure 6. SEM photograph of buccal surface of replicated banded mandibular first molar at $10 \times$ magnification as seen before treatment. $\mathbf{E}$ indicates enamel, $\mathbf{S}$ indicates band, and $\mathbf{Z}$ indicates zinc phosphate cement.

able, but they did find the necessary pressure used with the rubber cup and pumice method to be uncomfortable or painful. Weaks et al. ${ }^{20}$ found a substantial reduction of gingival bleeding and marginal redness in orthodontic patients who underwent polishing with an air-powder polishing system as compared to those orthodontic patients who were undergoing polishing every 3 months with rubber cup and pumice. The substantial reductions in gingival bleeding and marginal redness were attrib- uted to the thoroughness of plaque removal with the air-powder polishing system.

Interestingly, the air-powder polishing method did not remove appreciable amounts of composite or zinc phosphate cement, as was expected. This is in contrast to a study by Barnes et al. ${ }^{3}$ in which both composite and cement were found to be vulnerable to air-powder polishing. The difference in results of these two studies can be attributed to fact that the air-powder-water stream 


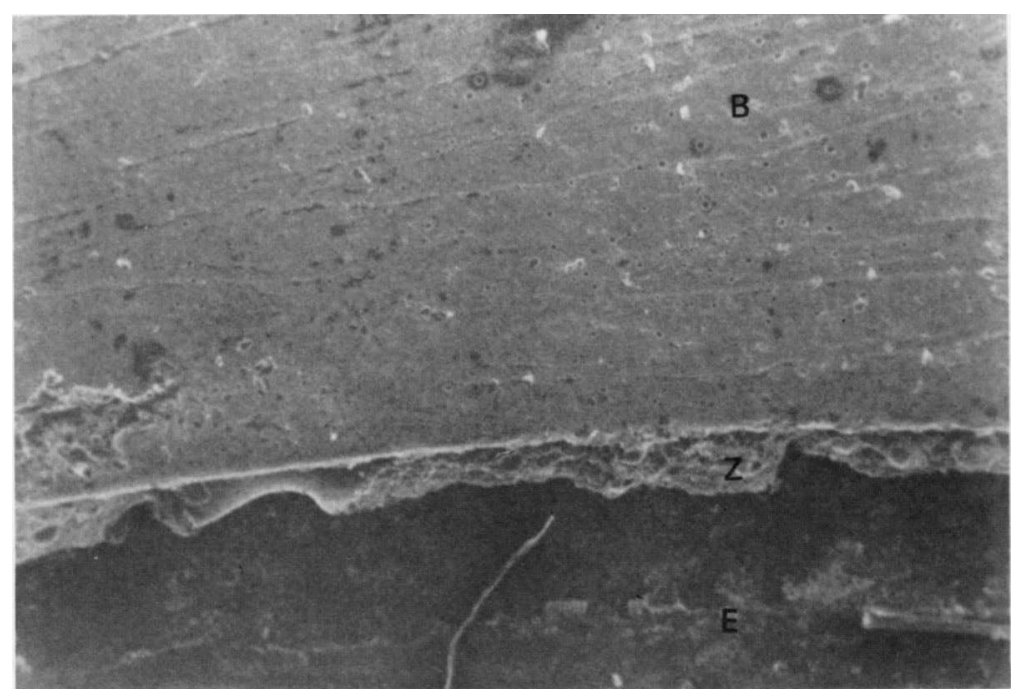

Figure 7. SEM photograph of buccal surface of a replicated banded mandibular first molar at 50× magnification as seen after treatment with the APP method for 60 seconds. Zinc phosphate cement remains intact.

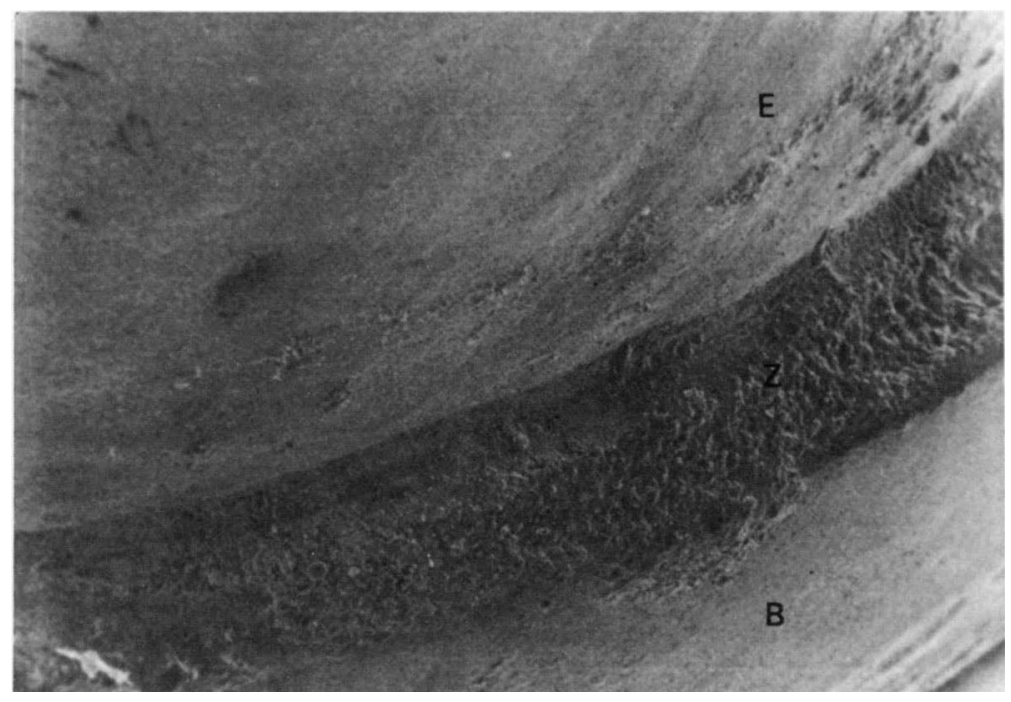

Figure 8. SEM photograph of replicated banded mandibular first molar as seen from occlusal view at 50× magnification before treatment.

was directed to the bracket and band at a 90-degree angle. This is contrary to the manufacturer's instructions, ${ }_{1}{ }^{17}$ which suggests a $60^{\circ}$ angle on anterior teeth and an $80^{\circ}$ angle on posterior teeth. The use of the $90^{\circ}$ angle that was centered on the brackets and bands most probably produced a diffusion of the spray, which did not disrupt the integrity of the composite bond to the enamel or the zinc phosphate cement to the enamel. Of particular importance is the fact that the composite and cement were left intact even after 60 seconds' exposure to the air-powder-water spray. Confirmed projections by Atkinson ${ }^{5}$ and Berkstein ${ }^{21}$ estimate that 30 seconds of exposure time to the air-powder-water spray is the equivalent of a patient's being maintained on a 3-month recall for 15 years and receiving a 0.5 -second blast from the polishing device at every visit. Certainly, no routine orthodontic treatment is carried out for 15 years; thus the 60-second exposure time is extreme. Even after this extreme exposure, no appreciable disruption of the composite occurred. Likewise, with the orthodontically banded teeth, the zinc phosphate cement did not demonstrate a loss of integrity. 


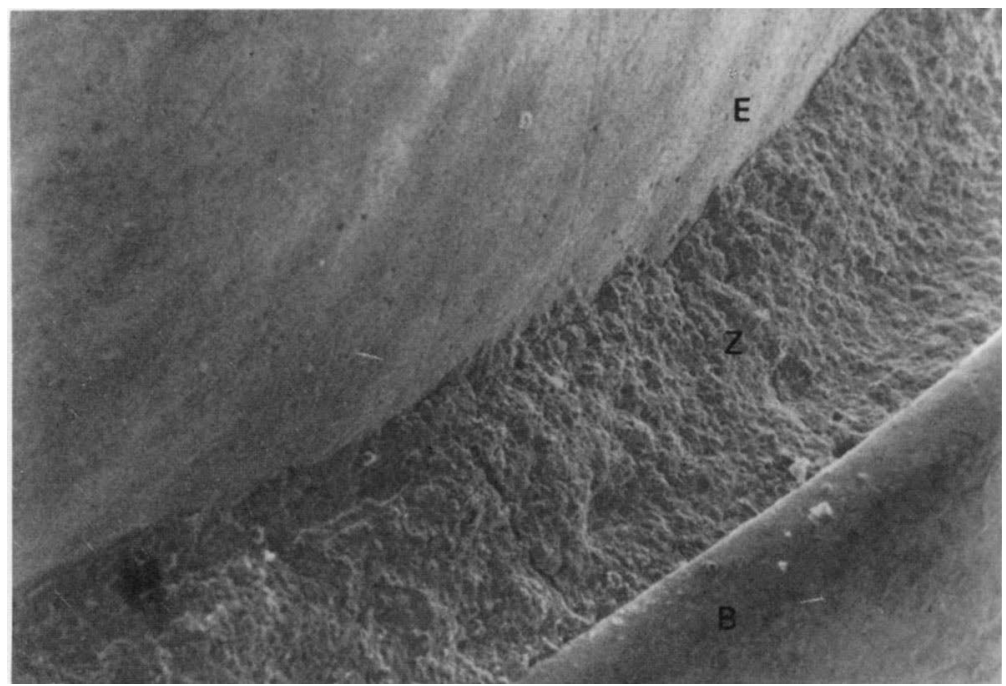

Figure 9. SEM photograph of replicated banded mandibular first molar in Figure 8 after treatment with the APP method for 60 seconds. Zinc phosphate cement particles are exposed, but margin remains intact.

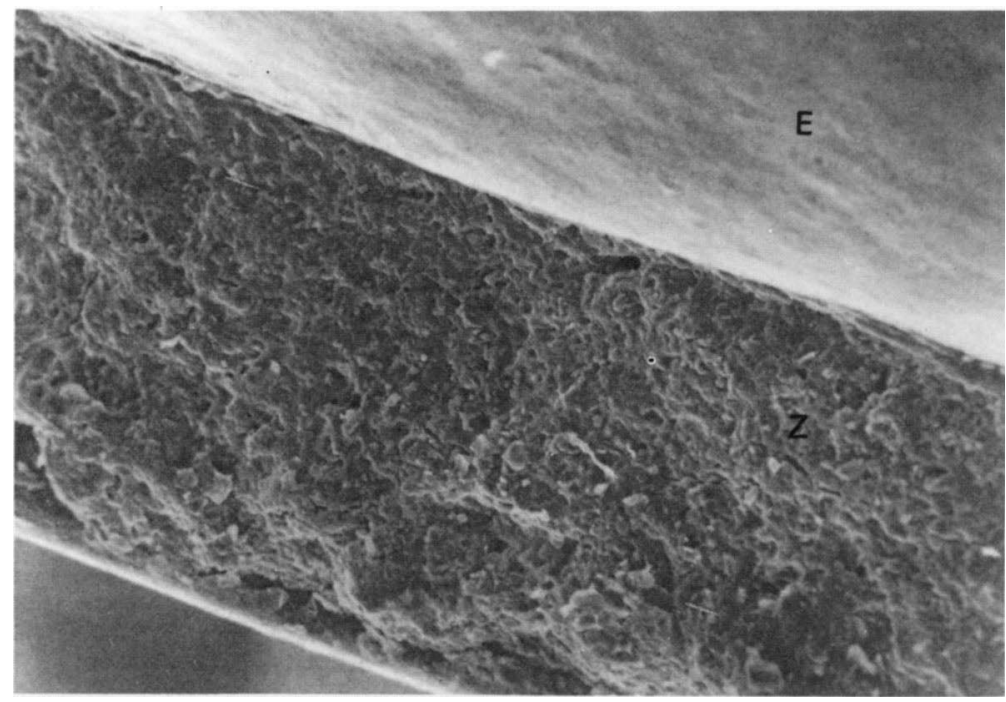

Figure 10. SEM photograph of replicated banded mandibular first molar shown in Figures 9 and 10, after 60 seconds treatment with the APP method, at 100× magnification.

\section{Conclusion}

This two-part study investigated the efficacy and efficiency of an air-powder polishing system on orthodontically bracketed and banded teeth and the effects of this polishing system on composite and zinc phosphate cement used with these brackets and bands. The following conclusions can be drawn:

1. Use of the air-powder polishing system on orthodontic brackets and bands is a time-efficient and effective means of plaque removal.
2. Use of the air-powder polishing system is not detrimental to either composite resin or zinc phosphate cement used to attach orthodontic brackets and bands when the spray is directed at a $90^{\circ}$ angle to the bracket or band with the nozzle kept at a distance of 3 to $5 \mathrm{~mm}$ from the bracket or band. 


\section{References}

1. Dentron Inc. The answer! Prophy-Jet Mark IV. Corpus Christi, Texas: Dentron, 1977.

2. Weaks LM, Lescher NB, Barnes CM, et al. Clinical evaluation of the Prophy-Jet as an instrument for routine removal of tooth stain and plaque. J Periodontol 1984;55:486-8.

3. Barnes CM, Hayes EF, Leinfelder KF. Effects of an air-abrasive polishing system on restored surfaces. J Gen Dent 1987;35:186-9.

4. Cavitron Cavi-Jet dental prophylaxis unit: instructional manual. York, Pennsylvania: Dentsply Corporation, 1983.

5. Atkinson DR, Cobb CM, Killoy WJ. The effect of an air-powder abrasive system on in vitro root surfaces. J Periodontol 1984;55:13.

6. Barnes CM, Holroyd SV. Comparison of coronal polishing with an air-driven handpiece and pumice and an air-abrasive system. Unpublished research, 1982.

7. Munley M, Everett M, Krupa C, et al. Removal of stain by air powder polishing [Abstr. 356]. J Dent Res 1987;66:151.

8. De Spain B, Nobis R. A comparison of rubber cup polishing and air polishing [Abstr. 357]. J Dent Res 1987;66:151.

9. Hakansson JP. A clinical, histologic evaluation of treatment using the Prophy-Jet. Tandlakartidningen 1983;75:1084-90.

10. Vande Velde F, Adrianes P, De Boever J. Clinical, histological and scanning evaluation of the Prophy-Jet in vivo and in vitro. Rev Belge Med Dent 1986;37:153.

11. Mishkin DJ, Engler WO, Javed T, et al. A clinical comparison of the effect on the gingivia of the Prophy-Jet and the rubber cup and paste technique. J Periodontol 1986;57:151-4.

12. Newman PS, Silverwood RA, Dolby AE. The effects of an air-abrasive instrument on dental hard tissues, skin and oral mucosa. Dent J 1985;159:9.
13. Willman D, Norling B, Johnson W. A new prophylaxis instrument: effect on enamel alterations. J Am Dent Assoc 1980;101:923.

14. Toevs SE: Root topography following instrumentation. Dent Hyg 1985;59:354.

15. Cooley RL, Lubow RM, Patrisi GA. The effect of an airpowder abrasive system on composite resin. J Am Dent Assoc 1986;112:362.

16. Lubow RM, Cooley RL. Effect of an air-powder abrasive instrument on restorative materials. J Prosthet Dent 1986:55:462.

17. Orton GS. Clinical use of an air-powder abrasive system. Dent Hyg 1987;61:513.

18. O'Leary TJ, Drake RB, Naylor JE. The plaque control record. J Periodontol 1972:43:38.

19. Greene J, Vermillion J. The simplified oral hygiene index. J Am Dent Assoc 1964;68:7-13.

20. Weaks MJ. The effect of an intensified maintenance program on the periodontal health of orthodontic patients. Unpublished report submitted to Dentsply/Cavitron, November 1984.

21. Berkstein S, Reiff RL, McKinney JF, Killoy WJ. Supragingival root surface removal during maintenance procedures utilizing an air-powder abrasive system or hand scaling. J Periodontol 1987:58:327-30.

22. Uchida T, Suda Y, Motohashi K, et al. The effect of an airpolishing system on orthodontic materials and tooth surfaces. Shigaku 1986:74:377-90.

23. Galloway SE, Pashley DH. Rate of removal of root structure by the use of the Prophy-Jet device. J Periodontol 1987:58:464-9. 